\title{
Good grief: bereavement literature for young adults and $A$ Monster Calls
}

Giskin Day, Centre for Co-Curricular Studies, Science Communication Unit, Imperial College London

Stories are important, the monster said. They can be more important than anything. If they carry the truth. (Ness, p151)[1]

\section{ABSTRACT}

Recent years have seen a proliferation of critically acclaimed novels for young adults dealing with bereavement. This is part of a 'bereavement turn' - a contemporary cultural movement to publically examine our attitude to death and grieving. This paper examines the narrative strategies in Patrick Ness's award-winning novel $A$ Monster Calls, to look at the ways in which the psychic burden of the impending loss of a parent through cancer is managed. The book draws on conventions of children's literature to create a sense of familiarity that helps to balance the emotional stress of the story. The Kübler-Ross stages of grief serve as a heuristic that helps the story deliver catharsis in spite of its inevitably traumatic subject matter. A Monster Calls is an important addition to the canon of fictional pathography.

\section{THE 'BEREAVEMENT TURN'}

The Medical Humanities have a deep and abiding interest in illness narratives, not only about patients but also exploring the perspectives of caregivers and family. Whilst the study of pathographies is now well developed,[2-4] illness narratives in fiction for young people are less well studied. Writing in 1999, McEntyre found that a relatively small number of books for young adults directly addressed illness and dying, with most found only in libraries rather than enjoying critical and commercial success.[5] But in the last decade, and particularly within the past year, a number of novels have been published for this audience to considerable literary acclaim. One of these is A Monster Calls by Patrick Ness.[1] It has won numerous prizes including the prestigious Carnegie Medal for outstanding writing for children, the Galaxy British Book Award for Children's Book of the Year, and the Red House Children's Book 
Award. Whilst many novels in the young adult (YA) genre deal with the aftermath of the loss of a parent, through divorce or death, A Monster Calls is unusual for taking as its subject matter the impending death of the protagonist's mother. The narrative strategies employed in the novel reference the now-familiar schema of the KüblerRoss stages of grief.[6] However, the book cleverly subverts other familiar tropes drawn from fairy tales and folklore, bringing psychological sophistication to a story that might otherwise be sentimental and rather mawkish. I will argue that Ness's success with A Monster Calls is part of a 'bereavement turn' in culture, where death is no longer a taboo topic and we are starting to address the way we come to terms with grief.

Since the 1960s, the 'problem novel' has characterized much YA popular fiction. This form of realistic fiction, which often features bereavement, has been derided by literary critics for pedestrian language, superficial treatment of important issues, exaggerated problems and formulaic plots.[7] However, as McEntyre noted,[8] there are some very fine young adult novels that can be helpful, to teens and those who work with them. Certainly, literary prize lists do show evidence of a fresh wave of writing about death by acclaimed authors. Of the eight novels shortlisted for the 2012 Carnegie Medal almost all of them deal directly or indirectly with bereavement. My Sister Lives on the Mantelpiece by Annabel Pitcher is the story of the disintegration of a family after the death of their teenage daughter in a terrorist bombing; Everybody Jam by Ali Lewis has the teenage narrator grieving for his older brother who died in a farm accident; My Name is Mina by David Almond involves a young girl coming to terms with the death of her father; and both The Midnight Zoo by Sonia Hartnett and Between Shades of Gray by Ruta Sepetys are set in World War Two with the burden of loss that war stories inevitably bring.

The proliferation of books about death and grieving for young adults can be seen as part of a wider movement in which mortality is being explored. The 'denial of death' thesis is based on the notion that modern humans deny death as a fundamental component of our physiological selves. This intellectual position tends to be viewed as normative, but it has come in for increased criticism from sociologists who hold that death is not denied or even particularly hidden within modern western society. Sayer refers to the deaths of celebrities like Michael Jackson and Jade Goody as 
part of a wider movement in which death becomes more 'public'.[9] Concerns about the effects of an ageing population and what constitutes a 'good death' are regularly played out in the media, but there is also a fascination with untimely death, or the prospect of it, when young people, or the parents of young children, are terminally ill. In the UK, the discussion of death is rarely out of the media. Hospital documentaries, such as Channel 4's 24 Hours in A\&E, do not shirk from showing deaths. In December 2010, the BBC broadcast the final moments of an 84-year-old cancer sufferer. Weeks later it showed 'Terry Prachett: Choosing to Die' in which the celebrated fantasy author, popular with young adults, was present at an assisted death at the Dignitas clinic in Switzerland. In January 2012, London's Southbank Centre hosted a four-day, phenomenally successful event: 'Dying: a Festival for the Living', at which a number of activities were tailored for children. The internet has also helped make mourning a collective process. Gibson has explored how the internet is a site of mourning and memorialisation, for example through Facebook tribute pages, channelling a culture that encourages sharing stories as a means of therapy.[10]

Today's adolescents have grown up in the wake of the 9/11 terrorist attacks with the maelstrom of insecurity and political instability it has engendered. For all too many adolescents around the world, bereavement is a sad reality as a result of disease, poor nutrition and war. In relatively affluent nations where longevity is increasing, many children are older when they experience bereavement through the deaths of their great-grandparents. There is an acknowledged role for books in helping young people to cope with grief. The bibliotherapy movement is now gaining growing currency in the UK as NHS Trusts adopt the 'Books on prescription' scheme. Bibliotherapy is aimed at mainly an adult audience, although there are some schemes developed for teenagers and young people.[11, 12] Recommending books for people who have been bereaved, or who are themselves terminally ill, is a tricky business. A book that may be helpful to one person may seem crass or insensitive to another. Broadway drew up some guidelines on using books to help young people cope with grief.[13] Her criteria for fiction include that it should: expand the young person's understanding of grief and bereavement; incorporate the tasks of grieving into the plot and character development and suggest constructive ways to cope; avoid glamorizing unsafe or unhealthy behaviours, such as isolation, risk-taking, 
substance abuse, inappropriate sexual conduct, or suicidal behaviour; and encourage self-reflection and discussion.

Well-written fiction about bereavement is not usually either written or marketed as 'self-help' for those experiencing grief. Only a small proportion of the readership will have had the misfortune to experience the loss of a parent, but almost all will have feared it. What is original about $A$ Monster Calls is that it deals with loss through death of a parent as the focus of the plot, rather than a subsidiary narrative. This is unusual in a book aimed at the younger end of the teen spectrum. In making the central dilemma the tension between Conor wanting his mother to die - for it all to be over - and his terror of losing her, Ness directly confronts the central fear and the sometime fantasy of every child: that of the death of a parent. Spufford argues that the psychic work in imagining bereavement is important: 'The situation of abandonment seems to be a necessary one to imagine, to hug to oneself in the form of a story. It focuses a self-pity that everyone wants to feel sometimes, and that perhaps helps a child or an adolescent to think through their fundamental separateness.' (p28)[14]

\section{PLOT SYNOPSIS: A MONSTER CALLS}

In the opening of $A$ Monster Calls, 13-year-old Conor O'Malley is visited by a monster who materializes from a yew tree that stands in the graveyard at the back of his house. But Conor has been expecting a different monster, one from a recurring nightmare. Conor's mother is being treated for cancer, although the word is never mentioned in the book. Conor's father lives in America with his new family and figures only briefly in the story. His grandmother is resented by Conor because he considers her to lack imagination, and he resents that he will have to live with her if his mother dies.

The monster makes his terms plain: he will tell Conor three stories, and in return, Conor must tell him a fourth story.

The first story told by the monster is the most well developed. A king has four strapping sons, but they are all killed in battle, leaving only an infant grandson. The 
king's wife and the baby prince's mother both 'succumb to grief' (grief can kill in this story), and the king marries again. His new wife is thought to be a witch and has used 'grave majicks' to make herself appear younger (there is a parallel here with Conor's grandmother who dyes her hair and isn't the way 'grandmas are 'supposed to be', p48). When the king dies, thought by his subjects to have been poisoned by the queen, she rules as regent. Reluctant to give up the throne, she decides that the prince, her step-grandson, should marry her rather than the farmer's daughter with whom he has fallen in love. The prince and the farmer's daughter run away together and consummate their union in the shadow of a yew tree. When the prince awakes, his lover has been murdered. He accuses the queen of murdering his bride and enlists the help of the villagers to burn her at the stake. At this point the monster saves the queen and carries her off to safety. In the face of Conor's bewilderment at this turn of events, the monster explains that the prince had murdered his own bride for the sake of overthrowing an evil that threatened the kingdom. The story shows, according to the monster, that the distinction between good and evil is not always clear cut. Also, many things that are true feel like a 'cheat' - an accusation levelled by Conor at the story.

The second story told by the monster is of an embittered apothecary who becomes increasingly isolated as his patients seek out newer remedies from modern healers. He wishes to cut down a yew tree in the graveyard to make remedies, but the parson repeatedly denies him access to the tree. When the parson's daughters fall ill and nothing else has worked, the parson approaches the apothecary and offers him anything if he would only save his daughters. The apothecary refuses to help because the parson has compromised everything he believed in. His belief was selfish and fearful.

At the end of the second story, Conor is invited to direct the monster in the destruction of the surroundings, the parson's house. The house and Conor's grandmother's sitting room merge and Conor wreaks very real destruction, including destroying a family heirloom.

Meanwhile an insidious form of bullying is taking place at school at the hands of clever but sly Harry. Harry has worked out that Conor wishes to be punished 
because he feels he deserves it. Whilst the initial bullying came in the form of physical violence, now Harry decides to ignore Conor who has been feeling increasingly invisible at school because people are constantly making allowances for him based on his mother's situation. The third tale then, is of an invisible man who called for a monster who will make people see him. Conor beats up Harry in the expectation that it will lead to him being punished, but when he is once again excused his bad behaviour on the grounds of his mother's situation, he realizes that there are worse things than being invisible: now everyone could see him but he was further away than ever.

At the climax of the book, Conor finds himself in the 'real' nightmare - the one he was expecting at the start of the story - where he is on a cliff edge holding on to his mother who is screaming for him not to let go. The nightmare monster pulls at her and Conor eventually has to let go. Throughout the trauma, the yew tree stands behind Conor and exhorts him to tell the truth in order for him to escape the nightmare. Conor resists telling the truth, saying it will kill him if he does. The monster says it will kill him if he does not. Eventually Conor admits that he cannot stand it in more: 'I can't stand knowing that she'll go! I just want it to be over! I want it to be finished!' He welcomes the oblivion that follows because he is receiving the punishment he deserves.

When he opens his eyes and finds himself still alive, Conor acknowledges to the monster that he has always known that his mother was going to die and he feels it is his fault for letting her go. By referring back to the stories he has told Conor, the monster says that humans are complicated beasts with minds that contradict themselves constantly. The monster tells Conor that what he thinks is not important, it is what he does that matters, and what he must do is to speak the truth.

His grandmother finds him sleeping under the yew tree and drives him to the hospital where his mother is dying. The monster tells him that if he speaks the truth, he will be able to face whatever comes. In saying 'I don't want you to go' and holding tightly to his mother, he could finally let her go. 


\section{THE KÜBLER-ROSS STAGES OF GRIEF}

When the loss through death of a parent prefigures the narrative, or occurs at the beginning of the book, the reader is not yet sufficiently invested in the character for the death of the protagonist's parent or parents to be psychically traumatic to the reader. Ness's A Monster Calls, however, does not shy away from dealing with this trauma. Ness uses a range of narrative devices to ameliorate the psychic trauma and bring the story within parameters with which young readers can still take satisfaction, even pleasure, in the narrative. These include the supernatural element of a largely benevolent monster, and the incorporation of fairytales although the 'happy endings' of these are subverted as a portent of Conor's mother's fate. Importantly, the narrative also incorporates the five stages of grief - denial, anger, bargaining, depression and acceptance. These serve as touchstones within the story, setting up a cultural resonance and helping to marry the fantastical and the realistic strands of the story.

The stages of grief were first articulated by Elisabeth Kübler-Ross in her seminal work On Death and Dying, first published in1969. Kübler-Ross worried about children growing up in societies in which 'death is viewed as taboo, discussion of it is regarded as morbid, and children are excluded with the presumption and pretext that it would be "too much" for them' (p6).[14] To be excluded from exposure to death is to lead to suffering from unresolved grief for which the child has no means of coping. Kübler-Ross's five stages of grief are well known and deeply embedded in culture. Originally based on interviews with terminally ill patients about how to come to terms with impending death, the model was been expanded to include the bereaved as well, and is now frequently invoked for dealing with any kind of loss.

The Kübler-Ross stages of grief are recognizable in A Monster Calls. Ness might not have set out to deliberately represent the stages to structure Conor's coming to terms with his mother's impending death, but the stages have perhaps become inextricably bound up with Western notions of grief. Rosenberg argues, 'The five stages of grief are so deeply embedded in our culture that they've become virtually inescapable.'[15] She goes on to be very critical of the stages of grief, arguing that there is very little 
evidence to suggest that they reflect the ways in which people grieve in reality.[15, 16] However, perhaps partly because there is a staged process implicit in KüblerRoss's model, it chimes with a narrative arc and has a heuristic value that is particularly evident in A Monster Calls.

\section{Denial}

Denial, on the part of Conor and his mother, is manifest. In conversations with his grandmother, Conor will not entertain the idea of a 'possible after' (p50). 'The treatments are making her better,' he says of his mother's illness, '... when this is all over ... you'll leave and we'll be fine' (pp52-53). Conor's mother is also in denial: she tells Conor that she is going to be okay and reassures him. She asks him to keep an eye on the yew tree in their back garden while she is in hospital: 'And Conor knew this was her way of telling him she was coming back, so all he did was nod and they both kept looking out at the tree' (p88). Denial is directly addressed in the monster's teaching: 'Sometimes people need to lie to themselves most of all,' he says to Conor, when they are discussing the first story (p72). The role of the monster will be to guide Conor through the various stages of coming to terms with his mother's illness. He will overcome Conor's denial through forcing him to 'speak the truth'. He will also voice for Conor what is unsayable and, at times, unthinkable.

\section{Anger}

The stage of 'anger' is represented at various points in the story, mainly in the episode where Conor, seemingly unknowingly, destroys his grandmother's sitting room, and also when he beats up Harry as a way of assuaging his guilt over his conflicted feelings about his mother's illness. Anger as a part of the grieving process is explicitly acknowledged in a conversation that Conor and his mother have when they acknowledge that the treatment wasn't working:

'It's okay that you're angry, sweetheart,' she said. 'It really, really is. [...] l'm pretty angry, too, to tell you the truth [...] You be as angry as you need to be,' she said, 'Don't let anyone tell you otherwise. Not your grandma, not your 
dad, no one. And if you need to break things, then by God, you break them good and hard.' (p177).

Gilmore has argued that the monster of dreams and fantasies represents an amalgam of the 'chaotic danger of the id and the punishing superego' (p18).[17] The monster initially can be seen as the embodiment of Conor's superego. He is paternal and acts as a critic of Conor's psychic handling of his mother's illness. However, during the outbursts of anger, Conor's id runs rampant. The episode in his grandmother's living room is when it is made explicit that the monster is an aspect of Conor's psyche. There are earlier clues, though, when Conor's own thoughts show monsterish traits: 'For a moment, he felt as if he could grab hold of the very air and twist it around Lily and rip her right in two' (p77). There are other references in the book to Conor feeling as if he is being bent or torn in two, or splitting open, 'like his body was twisting apart' (p182), suggesting that the monster is a separable component of Conor himself.

\section{Bargaining}

Conor's relationship with the monster is founded on a bargain: the monster will tell Conor three stories and, in return, Conor must tell the fourth. But Kübler-Ross's third stage of grief, bargaining, is best exemplified by the second story the monster tells of the parson whose daughters are ill and who tries to bargain with the apothecary. Kübler-Ross believed that psychologically, bargaining may be associated with "quiet guilt' (p68),[6] and so it is in the story. 'You may have anything you like, if only you would save my daughters,' the parson says to the apothecary whose access to the yew tree he has previously denied. However, the parson is punished for his vacillation, his willingness to give up his every belief when times were hard, and his daughters die. The apothecary will not bargain. The story returns to the potential of the yew to heal when Conor's mother, as a last resort is given new medicine made from yew (the implication is that this is Taxol, a chemotherapy drug originally derived from the bark of yew). Conor rationalizes the coming of the monster as a healer: 'It had come walking as a tree of healing, the same tree that made the medicine for his mother, so why else? Please, Conor thought [...] Please.' (p153). 
The bargaining aspect of the narrative helps to explicate the story's complex relationship to the role of belief. McEntyre pointed out that 'in most novels about illness and death, the question of God arises' (p35).[5] Kübler-Ross found that most bargains are made with God.(6) Religious faith is dealt with tangentially in A Monster Calls in that it features in the monster's second story, but it is used as a metaphor for self-belief, rather than religious belief: 'Belief is half of all healing. Belief in the cure, belief in the future that awaits' ( $p 119)$. Ultimately belief does not cure Conor's mum, although she does think it has 'bought' her some time: 'It's probably what's kept me here so long, Conor' (p176).

\section{Depression}

The stage of depression is subtle in the story. Kübler-Ross distinguishes two types of depression: reactive depression in which practical losses are realized, and preparatory depression in which the terminally ill person prepares for 'final separation from this world' (p70).[6] This latter stage, says Kübler-Ross, is usually a silent one, in which there is little or no need for words on behalf of the patient. For the family, though, 'The more this grief can be expressed before death, the less unbearable it becomes afterwards' (p138). The nightmare that forms the climax of $A$ Monster Calls signals the preparatory separation that precedes loss in Kübler-Ross's scheme. The nightmare monster pulls Conor's mum into an abyss in spite of his best efforts to hold on to her. The account of the nightmare draws on metaphors that are frequently associated with depression: descent, blackness and heaviness.[18]

\section{Acceptance}

The final stage in Kübler-Ross's conception of grieving is acceptance. In A Monster Calls, acceptance comes with Conor's being able to 'speak the truth' as the monster has exhorted him to do all along. Whereas the truth in the nightmare constituted Conor owning up to his wanting his mother to go so that it would be over, the truth he speaks at her bedside is that he doesn't want her to go. The acceptance is confirmed in the final line of the book: 'Conor held tightly on to his mother. And by doing so, he 
could finally let her go' (p215). His epiphany comes when he realizes he will survive (p214):

'And he also knew he was going to get through it.

It would be terrible. It would be beyond terrible.

But he'd survive.'

\section{THE ROLE OF NARRATIVE AND EMOTIONAL HONESTY}

Narrative works in complex ways in A Monster Calls, both within the story and in the context of the story. The metatext on the cover already marks it out as an homage: 'Patrick Ness spins an extraordinarily moving tale of love, loss and hope from the final idea of Siobhan Dowd, whose premature death from cancer prevented her from writing it herself.' Most press coverage about the book has also focused on the poignancy of Ness taking over the project from Dowd, who had pitched the idea of the book to her editor but then died before she could write it.

In A Monster Calls, stories take on the attributes of characters. Conor thinks of stories 'with dread' when his English teacher sets her class a life-writing assignment. 'Stories are wild creatures, the monster said, When you let them loose, who knows what havoc they might wreak?' (p61). This will be prophetic, as Conor will participate in violence and destruction in future stories the monster tells. The monster's stories pose paradoxes: things are not what they seem, outcomes are unpredictable, and assumptions turn out to be fallacious. One of the paradoxes is that stories, for all their fictiveness, tell the truth: 'Stories are important, the monster said. They can be more important than anything. If they carry the truth' (p151).

The narrative emphasizes the importance of stories throughout, but it is the act of speech that is of primary importance: 'You do not write your life with words, the monster said. You write it with actions' (p202), and actions here constitute speaking the truth. This is in contrast to other elements of the story in which verbalization is actively resisted. The words 'cancer', 'death' and 'love' are implied and never stated. Conversations about difficult issues are postponed, sentences are left hanging, and, although the need for 'talk' is spoken about, the talk itself is never direct. Conor's 
mum absolves him of the need to talk: 'I know everything you need to tell me without you having to say it out loud' (p177). His teacher excuses him from the task of life writing. But the monster will not let him off so lightly: the moral is that you must speak truth in order for healing to take place. That the monster 'calls' in the title suggests both that he visits and that he summons Conor, and us - the readers, through a speech utterance.

The idea of it being imperative to tell a truthful story is rooted in Aristotelian notions of the therapeutic value of catharsis. Kearney holds that catharsis purges two of our most basic affects, pathos (pity) and eleos (fear), through inviting us 'a) beyond a pathology of pity to compassion and b) beyond a pathology of fear to serenity' ( $p 52$ ). [19] This works in a double frame of reference: Conor goes beyond fear to serenity in accepting his mother's impending death, and the reader experiences cathartic compassion through empathizing with Conor.

There is a tradition of thought developed by Lévi-Strauss that maintains that mythic stories offer society a structural, ahistorical, narrative response to existential anxieties.[20] Ness uses myth in a similar way in A Monster Calls. By incorporating folklore, fairytales and mythic structures, the narrative is made universal. 'I came to heal you,' the monster says to Conor (p182), and so he does, through the power of cathartic narrative. Kearney suggests that narrative catharsis involves a unique balancing of compassion and dispassion, identification and contemplation, particular emotion and universal understanding: the narrative representation, the 'as if' of fiction, enables a degree of detachment without which the trauma might be overwhelming.[19]

Wilson and Short have argued that a new pattern in children's literature, that they call a 'postmodern metaplot', begins with the child being abandoned and usually ends with the child leading the adults to a hopeful ending.[21] The proliferation of orphans in children's literature serve both to enable a quest narrative free from parental interference and, as Kimball found,[22] to explore the pain of isolation. In many ways A Monster Calls could be said to be characteristic of the 'postmodern metaplot' in which it is the adults that require children to nurture them and lead them to a place of 
security. Conor's place of security, though, serves his own emotional needs, not necessarily those of his mother. From Conor's mother's perspective, it might have been easier for her if Conor had said, 'It's okay for you to go,' rather than 'I don't want you to go'. But the story remains faithful to Conor's emotional truth. Until the moment he sits by his mother's deathbead, Conor's truth is changeable, in keeping with a postmodern conception of the relative nature of truth. But ultimately the story comes back to a modernist ideal: Conor speaks 'the final and total truth' (p214). The monster tells Conor that 'Your mind will contradict itself a hundred times each day. You wanted her to go at the same time you were desperate for me to save her. [...] And your mind will punish you for believing both' (p201).

Just as young children's literature remains faithful to the modern narrative of the safety of home, and young adult literature seems now to be dominated by the postmodern narrative in which children assume the role of adults, $A$ Monster Calls is poised between postmodern incredulity towards the safe haven of family and the modern ideal where the truth is monolithic and salvational. This duality is aptly in sympathy with the child/young adult audience at which the book primarily is aimed.

Although it is tempting to conclude that $A$ Monster Calls would be useful in palliative care, caution must be urged. It has been found that aesthetic emotions elicited by reading (e.g. sympathy, identification, empathy) are different from emotions derived from memories evoked by reading.[23] It cannot be assumed that readers in the midst of the trauma of losing a parent to terminal illness will find the book cathartic or helpful. An analysis of readers' responses on the internet to A Monster Calls might be a useful source of data on this. Similarly, research is needed on whether children and teenagers experience grief differently to adults.

A child's bereavement through a mother's terminal cancer is one of the most tragic situations imaginable. Ness has responded to the challenge of bringing to fruition an original idea of Siobhan Down by crafting an imaginative, poetic narrative that balances the realism of grief with enduring elements of myth and fantasy. Jim Kay's scratchy monochromatic illustrations, for which he won the Kate Greenaway Medal, give the book a gothic aesthetic that perfectly complements the emotional maelstrom 
conjured by Ness's narrative. As with any analysis of any single literary work, care must be taken not to over-extrapolate to popular culture in general. But what is clear is that $A$ Monster Calls lends itself to interpretation using Kübler-Ross's stages of grief, and, I would argue, the book's enthusiastic reception is an indication that these stages have clear cultural resonance. For its frank approach to bereavement, and its ambitious engagement with complex psychology, A Monster Calls is likely to come to be seen as a significant zeitgeist-capturing moment in contemporary society's response to grief.

\section{Acknowledgements}

Many thanks to Felicity Mellor, Patricia Law and Zara Kesterton for useful discussions on this topic.

\section{REFERENCES}

1. Ness P. A Monster Calls. London: Walker Books; 2012.

2. Brody H. Stories of Sickness. New York: Oxford University Press; 2002.

3. Hunsaker Hawkins A. Reconstructing IIIness: Studies in Pathography. Purdue University Press; 1999.

4. Myers KR. Illness in the Academy. West Lafayette, IN: Purdue University Press; 2007.

5. McEntyre MC. Out of season: illness in adolescent fiction. J Med Humanit 1999;20(1):33-48.

6. Kübler-Ross E. On Death and Dying. 1969. London: Routledge; 2009. Republished.

7. Sturm BW, Michel K. The structure of power in young adult problem novels. YALS 2009;7(2):39-47.

8. McEntyre MC. Friends in need: illness and friendship in adolescent fiction. Lit Med 2002;21(1):132-46.

9. Sayer D. Who's afraid of the dead? Archaeology, modernity and the death taboo. World Archaeol 2010;24(3):481-91.

10. Gibson M. Death and mourning in technologically mediated culture. Health Sociol Rev 2007;16:415-24. 
11. Hicks D. An audit of bibliotherapy / books on prescription activity in England. Arts Council England and the Museums Libraries and Archive Council; 2006.

12. Allen JR, Allen SF, Latrobe KH, Brand M, Pfefferbaum B, Elledge B, et al. The Power of Story: The Role of Bibliotherapy for the Library. Children and Libraries 2012;10(1):44-49.

13. Broadway MD. Dealing with death: books to help young people cope with grief. Teacher Librarian 2008;35(5):44-48.

14. Spufford F. The Child that Books Built. London: Faber and Faber; 2003.

15. Konigsberg RD. The Truth about Grief: The Myth of its Five Stages and the New Science of Loss. New York: Simon \& Schuster; 2011.

16. Konigsberg RD. New ways to think about grief. Time 2011; 29 January.

17. Gilmore DD. Monsters: Evil Beings, Mythical Beasts, and All Manner of Imaginary Terrors. Philadelphia: University of Pennsylvania Press; 2009.

18. McMullen LM, Conway JB. Conventional Metaphors for Depression. In: Fussell $\mathrm{SR}$, ed. The Verbal Communication of Emotions. Mahwah, NJ: Lawreance Erlbaum; 2002.

19. Kearney R. Narrating pain: the power of catharsis. Paragraph 2007;30(1):51-66.

20. Lévi-Strauss C. The Structural Study of Myth. Structural Anthropology USA: Basic Books; 1963;206-31.

21. Wilson MB, Short KG. Goodbye yellow brick road: challenging the mythology of home in children's literature. Child Lit Educ 2012;43:129-44.

22. Kimball MA. From folktales to fiction: orphan characters in children's literature. Library Trends 1999;47(3):558-78.

23. Mar RA, Oatley K, Djikic M, Mullin, J. Emotion and narrative fiction: interactive influences before, during, and after reading. Cognition Emotion 2011,25(5):818-33. 